\title{
TRANSLATION OF CAPABILITY REQUIREMENT INTO MANAGEMENT BY OBJECTIVES ENVIRONMENT
}

\author{
Fabian BAXA \\ Centre for Security and Military Strategy Studies, University of Defence, Brno, the \\ Czech Republic \\ fabian.baxa@unob.cz
}

\begin{abstract}
Capability-based planning focused on materialisation of Alliance's ambitions has already been a reality for national strategic planners for several years. This relatively new planning environment offers not only new, broader possibilities but also new challenges. Although there are several documents describing capability-based planning available but no one is focused on a methodology how recognised capability needs is possible to translate into a common planning system explored within national ministries of defence.

This article has an aim to overbridge this gap using a logical link between a package of required capabilities and existing hierarchy of goals, measures and tasks exploring a functional areas (DOTLMPFI) tool. Considering an idea the capability is a dynamic issue having its own specific life cycle it is necessary to think over various phases of its life. These phases influence directly a real level of the capability. Hence various phases have their own demands on allocated resources it is not sufficient to plan resources just for achievement of an appropriate level of the needed capability but it is also necessary to pay attention to other parts of the life cycle, especially sustainment.
\end{abstract}

\section{Keywords: capability planning, capability life cycle, functional areas DOTLMPFI, MBO}

\section{Introduction}

The term of capability is mentioned in many documents and with huge number of various adjectives and in different contexts. The aim of this article is to present not so obvious view on the capability but via its life cycle showing selected possibilities for capability analysis and planning using this not so often seen approach.

The end of a cold war era connected with disappearance of known, concrete and a clear opposer, together increased uncertainty because of dynamically changing global security situation [1], a new approach to defence planning has appeared. Previously used reaction on supposed threat materialised into corresponding force structure has been changed into less materialised reaction based on capabilities.
Principally agreeing with famous Paul Davis' work [2] is possible to state that "force-based" reaction on an imminent threat has been changed to "capability-based" reaction.

In NATO defence planning practice a transition from Force Goals to Capability Targets (CT) appeared with a CT 2013 defence planning cycle. With a transition of defence planning capability based approach NATO member states have been encouraged to harmonise their defence planning processes with the Alliance [3].

Considering a fact that the output from the defence planning process is a list of required capabilities to meet strategic goals of the organisation (in this case the country) then this list is possible to take as an important input a for capability planning process. This 
process differs from defence planning process therefore different methodology might be explored.

Having in mind the planning is a part of management in general, the idea of capability management could be considered, too. And indeed, it is not so difficult to discover the term capability management in available literature, even in two senses. One comes from human resources focused on capability of personnel [4] and the other is aimed on capability or organisation to fulfil its strategic goals. The second meaning is used in this article.

The Capability Management is not also a completely new approach for strategic management; it has been used in commercial sphere for quite a long time. The main idea of this approach is based on the idea that the organisation should use all possible resources available to carry out its goals, internal resources (when their carriers are parts of organisation's structure) as well as external resources which carriers belong to other organisations. In commercial environment for this situation is frequently used the term of "outsourcing".

The Capability Management as the part of management generally consists of its internal sub-activities as thought in [5] similarly to Demings' PDCA cycle [6].

Concerning planning environment many countries use some version of Drucker's Management By Objectives (MBO) [7] methodology improved for national conditions, this article relies on basic MBO principles generally.

Principally one capability carrier, as a "materialised platform" of each capability, consists at least of one person with his personal mental and physical abilities. A higher-level capability aggregated from several lower level capabilities can rely on capabilities from internal as well as external capability carriers. From organisational point of view the carrier of the aggregated capability contains of all related internal capability carriers supported by capabilities of all needed external carriers delivering additional capabilities.

This paper consists of two main parts; the first is aimed on functional areas DOTMLPFI [8] management tool used for a capability elaboration exploring a capability life cycle. The second part proceeding in exploration of the same tool and approach is focused on the proper capability planning.

\section{Capability life cycle}

Turning back to the first sense of the Capability Management a human resources field explores a term of a life cycle Capability Management [9] and the Personnel is one of already mentioned functional areas. Also the US Coastal Guard publication [10] works with capability life. Putting together the same approach is used in this paper.

Concerning a capability view on activities of an organisation it is not a new approach within management. Since very beginning in commercial sphere there is a necessity to perceive planning of necessary ability just only via subordinated parts of internal structure of the examined organisation but more generally, via required capabilities fundamentally without distinguishing their internal or external resources. Although there are differences but the basic idea of the capability management approach is to manage all necessary capabilities using one set of management tools in principal.

The life cycle of any capabilities can be seen through its functional areas as recommended by NATO and this tool is thought also in this article.

Principally, the capability life-cycle consists of four basic parts, commencement of capability as a starting point, a phase of capability deployment, a phase of its sustainment. Later, when the existing level of capability is considered as a capability surplus, a phase of capability reduction may occur and finally the concrete existing capability might be terminated. Graphically this life cycle is depicted on figure 1 with main factors influencing the level of capability. 


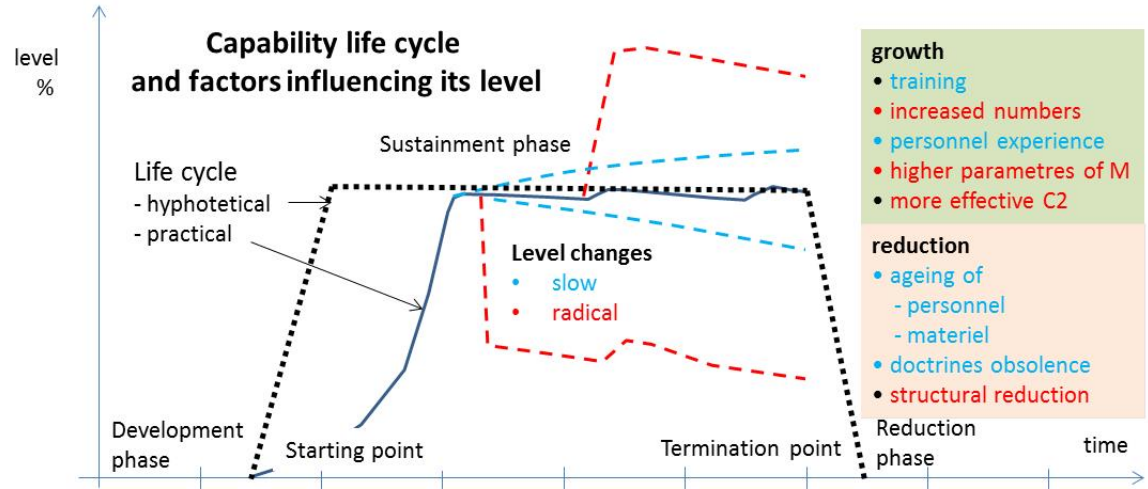

Figure 1: Capability life cycle with influencing factors

Level of capability, simply taken as a product of capability quality and capability quantity, may be influenced radically, by rapid changes as well as gradually, when changes appear in a longer-term period. These changes might have positive or negative influence on the capability level.

Various functional areas could be also studied via their proper life cycles. For illustration, the length of personnel life cycle is given by its contract depending on the rank and specialisation of concrete individuals. It may vary from several years for enlisted personnel, up to decade for NCOs, through decade plus for field officers and WOs to several decades for senior leaders. Cost of the life cycle consists of recruitment and initial education with preparation of individual person together with the cost of sustainment phase with refreshment training and education should be well-balanced not to spend too many resources on the development phase comparing to the phase of sustainment. The life cycle of the personnel functional area contains life cycles of all necessary personnel of the capability carrier.

Similar description is possible apply on other functional areas life cycles, too.

Therefore, to have the demanded capability prepared for use in required time means to synchronise life cycles of all functional areas in order to have them all in the sustainment phase for a desired period as illustrate on the figure 2 .

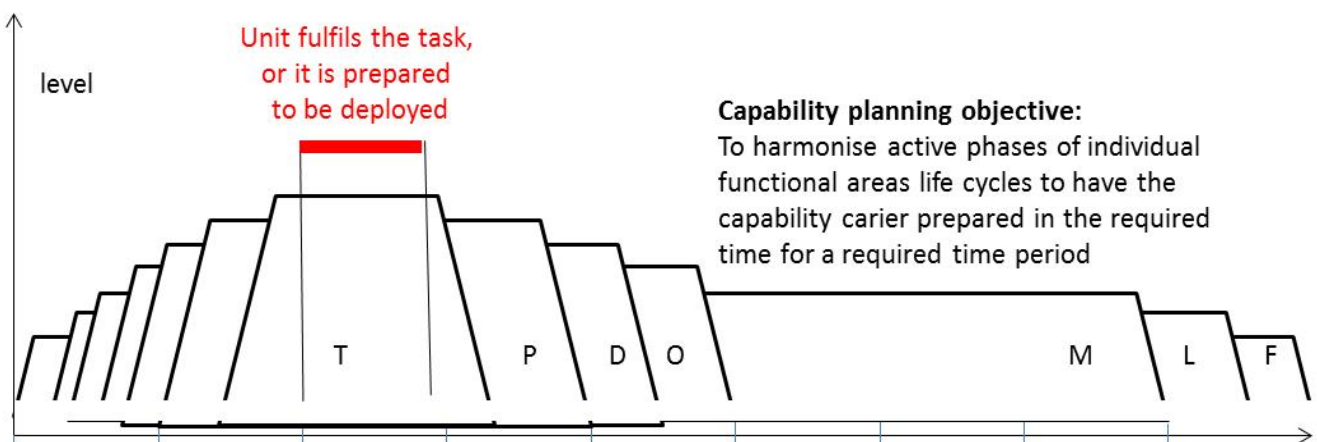

Figure 2: Synchronisation of functional areas life cycles

Having available all necessary issues of all functional areas in appropriate place does not mean to have a required capability prepared for the use. In this moment, it is the right time to consider Training as a common denominator of all other functional areas. Starting from harmonisation training at basic organisational level continuing with higher level of the training and finishing with battalion training with certification the commanding officer can report his battalion is combat ready. After passing successfully through certification process this unit is prepared for possible deployment to an operation or to be 
earmarked for readiness forces. The same process is applicable for higher echelon units of all services and task force.

Reflecting NATO rules the certification is generally valid for three years and then the whole process of training is necessary to repeat. It means the sustainment phase of this capability is limited by validity of certification. During the sustainment phase, it is to be self-evident that no radical changes are expected.

In practice, it means that all changes having radical influence on level of capability should be planned beyond the sustainment phase. These changes should be followed by harmonisation training at all appropriate levels and finished by the certification. Real impact of this fact is that it is not realistic to keep one concrete unit in high level of readiness longer than the certification validity. After this period, it is possible to manage all needed changes in all functional areas.

Mutual link between training life cycle and needed number the same kind of unit for rotation is an subject of NATO Istanbul initiative or Usability report mentioned in several NATO documents, e.g. in [11].

\section{Capability planning}

Accepting the life cycle view on capability using functional areas tool the aim of capability planning should be just to synchronise life cycles of all necessary issues through all functional areas for each capability from the whole list of required capabilities. It seems to be simple.
The challenge is to have information of each required capability elaborated into all necessary issues throughout all functional areas available, especially where the level of each capability in its proper life cycles is situated. This information should be possible found in databases of managers which are responsible for individual functional areas.

The Capability manager is established to manage all activities related to reach required capability level in given time. Within military conditions the role of the capability manager might be played by an appointed commander being responsible for the unit-carrier of required capability.

Simplifying this approach to the capability planning the following part of this chapter works with one capability carrier owning just one required capability at a lower level than needed.

Managers of all functional areas should also be able to define a goal to reach the needed level of the required capability projected into their functional area and elaborated this goal into goals tree consisting of lower levels of goals, measures and tasks in according the MBO theory. Having an overview of all related norms and standards they should be able to calculate resources and time needed to have all items, which each capability consists of, at needed level and to sustain them at this level for a needed time period as depicted on figure 3. Expenses of capability have to contain costs covering all phases, not only development as mentioned in many documents.

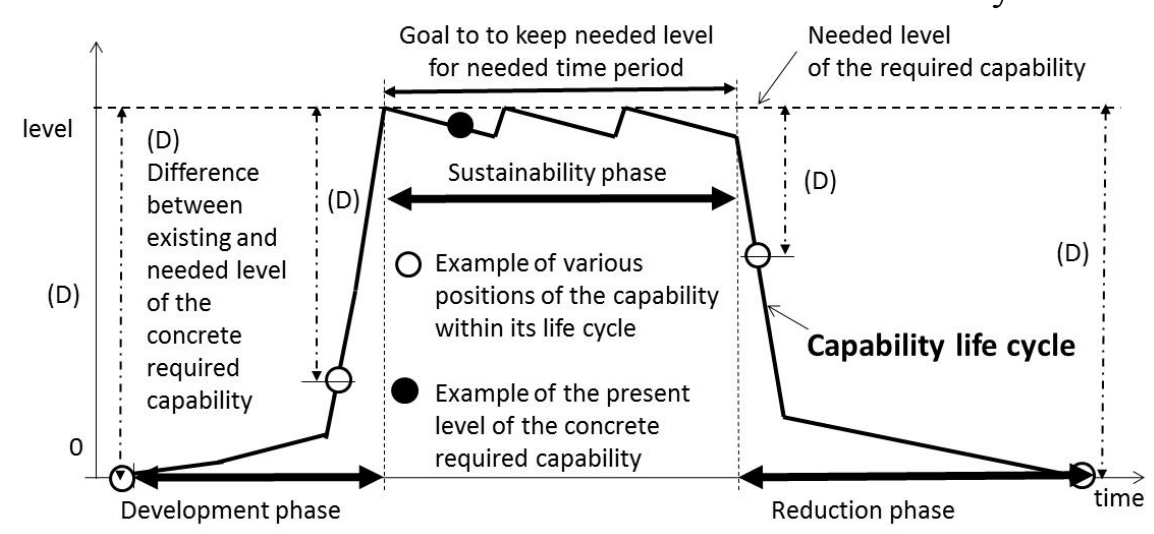

Figure 3: Possible position of required capability within its life cycle and related goals 
In order to launch Training to reach higher level of the capability supposes to have all other functional areas issues already available. There might be some minor exceptions, for example not all materiel, especially supplies should be necessary present at unit when starting training at basic level. In all functional areas is possible to find some exceptions it is up to capability manager in cooperation with functional areas managers to define them.

For the first time, some workload is expected to define all necessary goals, measures and tasks to reach needed level of required capability repeating that for all required capabilities. However once having goals tree for one capability, some of tasks and measures should be at least partially explored in case of other capabilities and capability carriers. Creating a database of capabilities containing history of their goals trees for various capability carriers linked up to needed costs and time each new capability will be elaborated much more easily. An example of a possible goals tree with identified executors for one required capability is on figure 4.

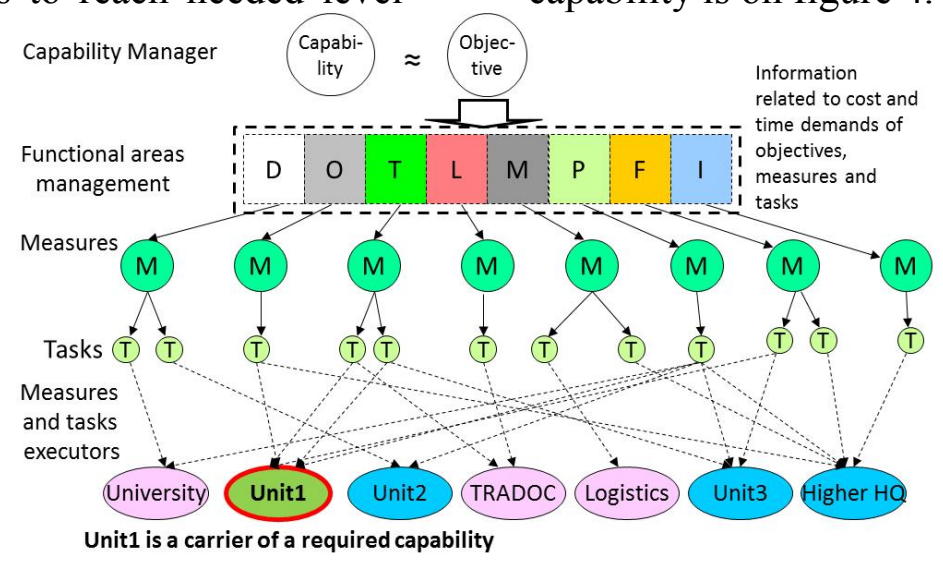

Figure 4: Illustration of possible goals tree for one required capability

For central planning authorities, the situation is approximately the same; having complete list of all required capabilities with appropriated goals trees, needed costs and time in the database it is relatively simple to generate inputs for specific planning documents. Especially it is suitable for planning of recruitment, education, training, development of doctrines and norms, organisational changes, acquisition, maintenance of materiel, facilities etc. A database of past, present and planned future capabilities with appropriate data enable to generate capability development plan as well as planning documents for individual planning horizons for armed forces, their units and task forces as seen on figure 5 .

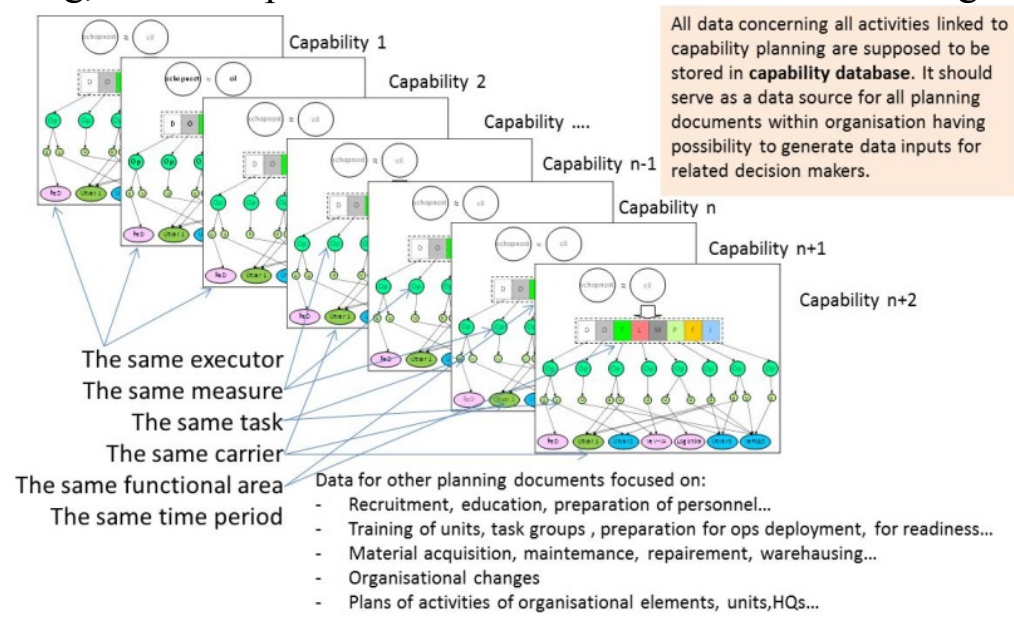

Figure 5: List of capabilities as a basis for the capability database 
Although the described procedure of capability planning explores quite simple ideas, when put in practice a huge workload might be expected to create the capability planning database. Once having data concerning one cycle of capability planning completed, with appropriate HW and SW support the whole process will be much easier.

\section{Conclusion}

The aim of this article is to present different view on planning of capability different from many times published capabilitybased planning showing their different reasons. The capability planning is not so elaborated as capability-based planning therefore there are not many references describing this planning approach.

This alternative approach to capability planning might be explored for further development of strategic management theory in general and its methodology as well as for the same level and purpose of planning carried out within an environment based on MBO principles.

\section{Acknowledgements}

The work presented in this paper has been supported by the Ministry of Defence of the Czech Republic (Research Project "STRATAL" No. 907930101023).

\section{References}

[1] STOJAR, Richard; FUČÍK, Jakub; DYČKA, Lukáš; PROCHÁZKA, Josef; KRAUS, Josef; FRANK, Libor; PROCHÁZKA, Dalibor; NOVOTNÝ, Antonín. Vybrané trendy vývoje bezpečnostního prostředí a možné implikace pro ozbrojené síly. Brno: Univerzita obrany, 2016, 118 p. ISBN 978-80-7231-394-5.

[2] DAVIS, K. Paul. RAND. Analytic Architecture for Capabilites-Based Planning, MissionSystem Analysis, and Transformation [online]. 2002. Santa Monica: National Defence Research Institute, 2002, 74 s. [cit. 2015-10-15]. Retrieved from: https://www.rand.org/content/dam/rand/pubs/monograph_reports/2005/MR1513.pdf

[3] NATO Defence Planning Process. In: North Atlantic Treaty Organisation [online]. 2017 [cit. 2017-02-16]. Retrieved from: http://www.nato.int/cps/en/natohq/topics_49202.htm

[4] Capability Management. In: Center for Talent Reporting [online]. Denver: SEO Company, 2017 [cit. 2017-03-07]. Retrieved from: https://www.centerfortalentreporting.org/capability-management/

[5] LALOR, Therese. Capability management v1.0. In: Generic Activity Model for Statistical Organisations [online]. [cit. 2017-03-07]. Retrieved from: http://www1.unece.org/stat/platform/display/GAMSO/Capability+management+v1.0

[6] System on Line: Demingův cyklus PDCA. SEDLÁČEK, Miroslav. EZU. Systemonline.cz [online]. [cit. 2015-03-25]. Retrieved from: http://www.systemonline.cz/spravait/deminguv-cyklus-pdca.htm

[7] Mulder, P. (2010). Management By Objectives (MBO). [cit. 2017-02-19]. Retrieved from: http://www.toolshero.com/management/management-by-objectives-drucker/

[8] What is transformation: An introduction to Allied Command Transformation. In: Instituto Español de Estudios Estratégicos . 2015

[9] URWIN, E.N., AHLEBERG PILFOLD, K.S. and HENSHAW, M.J., 2010. Through life capability management: bene ts and behaviours. IN: Andersen, M. (ed.) Contemporary Ergonomics and Human Factors 2010: Proceedings of the International Conference on Contemporary Ergonomics and Human Factors 2010, pp. 153-162.

[10] Capability Management: Coast Guard Publication 7-0 [online]. 2013 [cit. 2017-03-07]. Retrieved from: https://www.uscg.mil/doctrine/CGPub/CG_Pub 7 0.pdf

[11] Secretary General's Annual Report 2011. In: North Atlantic Treaty Organisation [online]. 2012 [cit. 2017-02-15]. Retrieved from: http://nato.int/cps/en/natohq/opinions_82646.htm?selectedLocale=en 